\title{
Don't Be Perfect: Just Be You
}

Jade Amerilda Scielzo Irving

The transition from high school to a college has been a challenging one for me. Independent of the issues from the pandemic, and having been somewhat underprepared academically, I have learned one important point that I hope will help others: Just be you.

Most of my high school years were spent on the ice. As the sun came up, you could typically find me at the ice skating rink; hours of jumping, spinning, and frequently, falling. Hour after hour, day after day, I typically spent around 60 hours a week skating. Bruises oftentimes covered my body. But I honestly kind of hated studying-so skating gave me purpose.

However, that all changed one day in my junior year. I had the opportunity to shadow a team of resident trainees at a university medical center, and suddenly realized where I wanted to be in life. Watching these physician trainees go from patient to patient-helping to save lives and giving hope to their patients - was the most powerful, inspirational thing I had ever seen. Empowered with incredible skills and knowledge, they were devoting their lives to helping others. This was what I wanted to do. I wanted this type of meaning in my life.

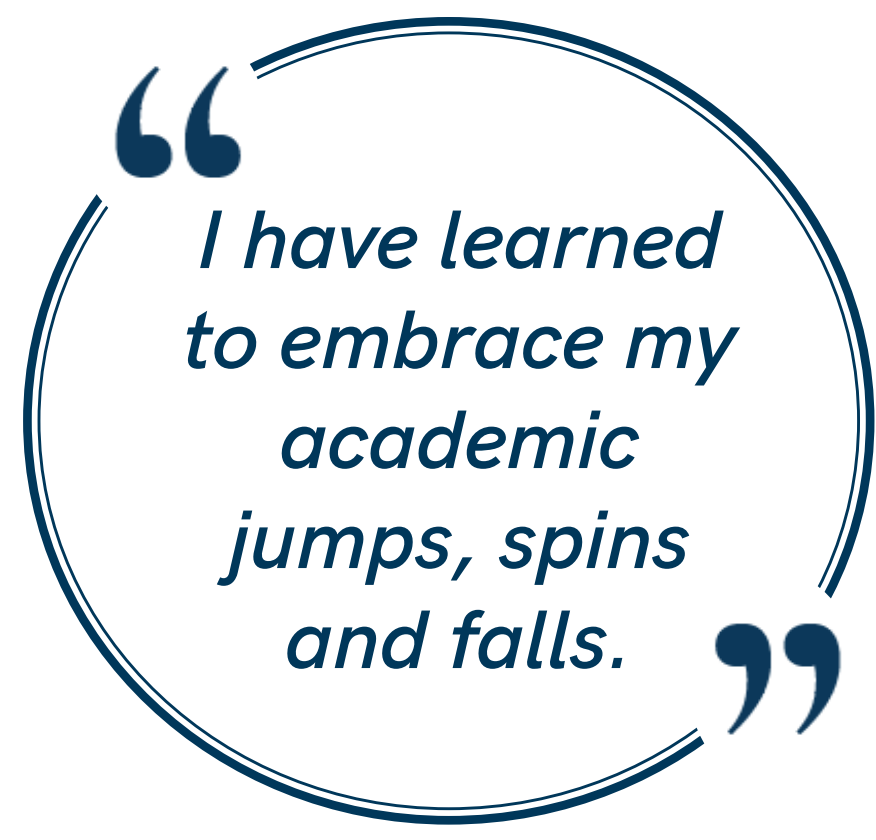

Now, I just needed to work on the skills and knowledge. Yikes... Catch-up commences. I suddenly felt like I had just taken one of the worst falls ever on the ice. I was paralyzed-and realized it was going to be pretty hard to get back up where I wanted to be. I enrolled in a small private school for my final year of high school and fully dedicated myself to studying. I eagerly applied to collegesand was so excited to get accepted. I started.

My first few weeks in college were terrifying. I had no idea what I was doing. There were assignmentstons and tons of assignments - that I wholeheartedly felt underprepared to complete. I studied, but I didn't really understand how to study. I tried to complete assignments, but I always felt they needed to be better. I hated my work-but the deadlines

came, and I submitted it. Sometimes I cried... I felt like I was going to a big figure skating competition without having learned my routine. How was I truly going to be worthy of being a physician if I couldn't even create an amazingly inspirational paragraph in Canvas? 
I reached out. I talked to my faculty. I talked to the few friends that I was able to make. (Making friends has been really challenging given the pandemic and being virtual.) I talked to my parents. I realized that I didn't need to strive for the perfection that I had always sought of myself-I realized that I needed to just do the best that I could within the parameters that I had. I just needed to keep strong-keep remembering my passion - and to keep pushing forward. Try, try again. I get up from the ice, and just pick up the pieces each time I fall. Excellence comes from practice. Learning comes from mistakes (and wow, I have made a lot).

I now do my best every day, but have self-compassion. I always reflect on what I did well-and pick a few things to do better. Every day I want to be a better version of myself-so that I can eventually be a wonderful physician. I have learned to embrace my academic jumps, spins and falls. Even then I am sure I will continually challenge myself to be the best I can be, but in the interim, I have decided that I will enjoy my education. I will find passion in every class-and will love the road that I am on. I don't want to be perfect-I just want to be me. So to all my peers and future aspiring students that have similar aspirational goals, I encourage you to join me in this quest. Let's make our educational experience as awesome as possible - and just work on being the best we can be together. Soon we'll master these jumps and spins, and take on the world!

Remember, just be you.
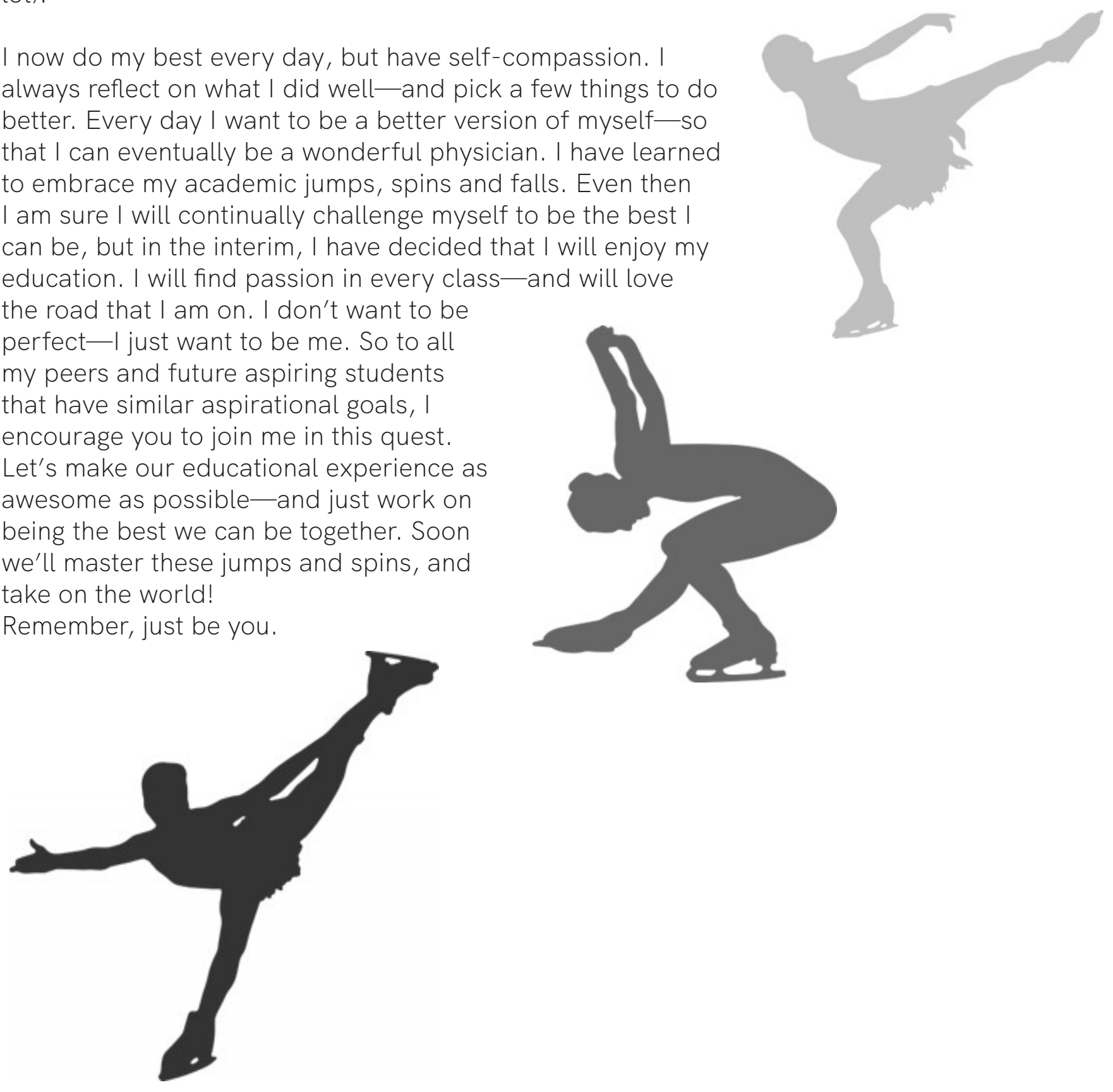